\title{
REFLEXÕES ACERCA DO ENSINO DE LIBRAS NO ENSINO FUNDAMENTAL
}

\section{ARTIGO ORIGINAL}

ANTUNES, Maria de Fátima Nunes ${ }^{1}$, ALVES, Taiane ${ }^{2}$, ARCARI, Inedio ${ }^{3}$, CARDOSO, Ronan Guimarães ${ }^{4}$, GARCIA, Alexandro Ferreira ${ }^{5}$

ANTUNES, Maria de Fátima Nunes. Et al. Reflexões acerca do ensino de libras no ensino fundamental. Revista Científica Multidisciplinar Núcleo do Conhecimento. Ano 06, Ed. 09, Vol. 03, pp. 05-26. Setembro de 2021. ISSN: 24480959, Link de acesso: https://www.nucleodoconhecimento.com.br/educacao/ensinode-libras, DOI: 10.32749/nucleodoconhecimento.com.br/educacao/ensino-de-libras

\section{RESUMO}

O presente trabalho objetiva analisar questões inerentes à inclusão do aluno surdo em salas de ensino regular no ensino fundamental em nosso país, bem como a utilização da LIBRAS nesse processo de inclusão. Nesse sentido, faz-se um breve relato histórico da inclusão do aluno surdo e analisam-se definições e questões inerentes à formação inicial e continuada dos educadores. Ainda, abordam-se questões inerentes às adaptações necessárias nas instituições de ensino para o atendimento destes alunos. Finalizando, discorre-se a respeito da Linguagem Brasileira de Sinais (LIBRAS) e sua importância nos processos inclusivos. Diante do exposto, tem-se como questão norteadora: Quais adaptações são necessárias para que a escola promova a inclusão do aluno surdo? Esse questionamento norteia as reflexões deste artigo. A pesquisa é de caráter descritivo e utiliza o método de revisão bibliográfica. Neste contexto, explora-se a situação do aluno surdo em salas

\footnotetext{
${ }^{1}$ Doutoranda em Ensino de Ciências Exatas-UNIVATES, Intérprete de Libras, Ensino; Inclusão e Surdez.

${ }_{2}^{2}$ Pedagoga Pela FCSGN, Pós-Graduada em Psicopedagogia da FCSGN, Tradutora Intérprete de Libras, Educação de Surdos.

${ }^{3}$ Doutor em Engenharia Elétrica- UNEMAT.

${ }^{4}$ Mestrando em Ensino de Ciências Exatas - UNIVATES.

${ }^{5}$ Mestre em Ensino de Ciências Exatas.
}

RC: 96849

Disponível em: https://www.nucleodoconhecimento.com.br/educacao/ensino-delibras 
de ensino regular, de acordo com a literatura já publicada. Após a análise das obras que embasaram o estudo, é perceptível que, apesar de todos os esforços, o atendimento ao aluno surdo não está ocorrendo de forma adequada, pois poucos educadores conhecem LIBRAS, estando, portanto, despreparados para tal atendimento. Constatou-se, também, que os currículos e estruturas não atendem às necessidades dos educandos surdos.

Palavras-chave: Aprendizagem, Alfabetização Escrita, Formação do Professor, Surdo, Libras.

\section{INTRODUÇÃO}

É um grande desafio discutir inclusão, pois as escolas devem ser transformadas em espaços inclusivos, que proporcionem aos alunos um contexto de aprendizagem com mais significado e motivação.

$\mathrm{Na}$ educação de alunos surdos, é preciso ater-se ao fato de que a língua materna é a linguagem de sinais. Ele deve alfabetizar-se como qualquer outro cidadão e, caso já domine esta linguagem, tudo flui melhor; caso contrário, as instituições de ensino devem promover métodos que possibilitem a inclusão deste aluno, ajustando-se às suas necessidades. Portanto, para que essa interação ocorra de fato, a utilização da LIBRAS é de extrema valia, por proporcionar a comunicação entre o surdo e a comunidade escolar.

A educação direcionada à inclusão dos alunos surdos está em fase de adaptação nas instituições de ensino, com novas metodologias e estratégias diferenciadas, uma vez que são responsáveis por capacitar os professores, proporcionando-lhes conhecimentos relativos à inclusão, a fim de que atuem não só com o estudante, mas também com a família, tendo cada qual sua responsabilidade. Esse trabalho em conjunto melhora o desempenho do aluno surdo em sala de aula.

O principal objetivo deste artigo é analisar questões inerentes ao processo de inclusão educacional do surdo em escolas de ensino regular no ensino fundamental, 
verificando dados sobre uso da língua brasileira de sinais (LIBRAS), como auxiliar nesse processo inclusivo através de literatura já publicada. Nesse sentido, abordamse conceitos e a história da inclusão com foco na formação de professores e na adaptação de currículos. Diante do exposto, tem-se como questão norteadora: Quais adaptações são necessárias para que a escola promova a inclusão do aluno surdo? Esse questionamento norteia as reflexões deste artigo.

Essa pesquisa é relevante na medida em que analisa a situação do surdo no ambiente escolar, no ensino fundamental, pormenorizando sua presença em sala de aula, para verificar se a situação é de fato inclusão, ou se trata apenas de integração ou até de segregação. O estudo também examina a utilização da LIBRAS, bem como se estão sendo contempladas as demais necessidades do surdo.

\section{CONCEITO E HISTÓRIA DA INCLUSÃO}

Para Peixoto (2002), a inclusão não passa de mais uma das muitas ideologias do sistema capitalista, sendo, na maioria das vezes, apenas uma forma de o estado livrar-se de suas responsabilidades. Assim, ao usar a denominação "portador de necessidades especiais", cria-se uma forma de isolá-lo em determinados espaços sociais. Schneider apud Peixoto (2002, p. 42-43) acredita que "se dermos conta de auxiliarmos o portador de necessidades especiais a reger-se ativamente, estaremos ajudando-o a colocar em questão a própria formação social que deu origem a conflitos individuais e sociais que the são impostos".

É preciso questionar a fundo a própria estrutura social. Ao fazê-lo, não se pode deixar de incluir todos, sem distinção, porque não só os excepcionais apresentam problemas de adaptação, também os ditos "normais" estão envolvidos no processo de alienação imposto pelo sistema. Segundo Peixoto (2002) é importante levar em consideração a produção social da deficiência e as dificuldades de integração dos indivíduos na sociedade, principalmente, daqueles que apresentam diferenças físicas ou corporais. Uma sociedade igualitária seria o estado ideal para a resolução deste problema, já que as exigências sociais sobre o indivíduo e o modo de relação 
entre eles assumiram uma dimensão muito mais humana e saudável. Peixoto (2002) afirma que a questão da inserção na rede regular de ensino faz parte do discurso oficial, ou seja, acarreta aos cofres públicos um ganho real.

Analisando o fator histórico, percebe-se que as pessoas com deficiência não eram bem-vistas na sociedade, pois ninguém compreendia as necessidades especiais. Assim, o comportamento da sociedade em relação a essas pessoas deixava-as impotentes e sem ação. Era-lhes negado o acesso aos bens e serviços, à educação e ao convívio na sociedade, configurando assim um grave exemplo de discriminação.

De acordo com Mato Grosso (2002), a prática da inclusão é imprescindível, mas, para que aconteça, são necessárias práticas sociais, que objetivem respeitar as diversidades humanas, para acabar com a exclusão. Assim, a escola é indispensável para que aconteça uma educação digna em relação aos discentes com necessidades educacionais especiais. Nesse sentido, pode-se planejar adaptações, que evidenciem que os resultados superam as expectativas dos professores.

Segundo as Diretrizes Nacionais para a Educação Especial na Educação Básica (BRASIL, 2002), devem ser criadas e implementadas orientações e ações que defendam e favoreçam a Educação Especial. Diante da discriminação histórica desses alunos especiais, surgiram leis referentes aos direitos humanos, com destaque para a Declaração dos Direitos Humanos (ONU, 1948), que assegura o direito à educação, pública e gratuita, para todos. Ou seja, defende-se e assegurase a inclusão das pessoas com deficiência, proporcionando-lhes oportunidades educacionais e sociais iguais a todos, o que contribuiu para o desenvolvimento de classes especiais em escolas públicas no Brasil e garantir o direito à educação para todos. Assim, a educação de crianças com deficiência vem tomando força com o movimento nacional de defesa dos direitos das pessoas com deficiência na escola, no trabalho e na comunidade, com o objetivo de alcançar igualdade e justiça social. 
As Diretrizes Nacionais para a Educação Especial na Educação Básica (BRASIL, 2002a) também destacam a Constituição Federal de 1988, que, no artigo 208, inciso III, garante "o atendimento educacional especializado aos alunos com necessidades educacionais especiais, preferencialmente na rede regular de ensino". Assim, as leis surgiram para contribuir cada vez mais com a inclusão dos que necessitam de educação diferenciada, bem como com a forma adequada de conhecer cada vez mais o direito dos alunos em sala de aula. Igualdade para todos, direito à educação, com certeza, é um marco valioso, que contribui para melhorar a vida de todos os cidadãos.

\section{A SURDEZ E A INCLUSÃO}

No Brasil, desde o início, a trajetória educacional percorrida pelos surdos, junto com sua influência social, guarda uma série de semelhanças com a trajetória percorrida pelos surdos nos Estados Unidos e na Europa. Essa situação se deve à crença geral de que crianças diferentes eram anormais e, portanto, deveriam ser excluídas da vida social e do sistema de educação formal (STROBEL, 2006).

De acordo com Strobel (2006), a educação de surdos no Brasil, além da forma original de visualizar o surdo e do método europeu desenvolvido ao longo dos séculos XVI a XVIII, continuou sendo influenciada desde o século XIX até meados do século XX pelo desenvolvimento de estudos da audição na Europa e nos Estados Unidos. Ainda, de acordo com o autor supracitado, tal pesquisa promove a lógica de considerar os surdos no Brasil como enfermos ou deficientes, enfim, como sujeitos que precisam de tratamento especializado e de cura.

A classificação do grau de surdez também surgiu para apontar o tamanho do desvio da audição dos surdos, em relação às normas estabelecidas pela sociedade. Atingido por esses pressupostos, o Brasil passou a sistematizar e a implementar medidas específicas para a educação de surdos, tendo um caráter normativo, caritativo e assistencialista, em instituições dedicadas a esse fim. Nesse contexto, desde o final do século XIX até meados do século XX, são mantidos 
estabelecimentos institucionais especiais, dependentes da atuação de professores profissionais na área da surdez. Vale ressaltar que, nesse período, o grupo de surdos também participava da educação regular, mas sem nenhum atendimento diferenciado. Ou seja, esses alunos tiverem oportunidade de receber educação formal, mas deveriam adaptar-se às características desse sistema de ensino em vez de este procurar atender às expectativas e necessidades dos surdos (STROBEL, 2006).

No que se refere à inclusão de alunos com necessidades especiais, a legislação brasileira, no artigo 208 da Constituição Federal de 1988, prevê que o atendimento deve ser prestado às pessoas com deficiência, preferencialmente, na rede regular de ensino. Além disso, a Lei de Diretrizes e Bases da Educação Nacional de 1996 também estipula que a educação deve ser integrada tanto quanto possível, e recomenda-se que os alunos com necessidades especiais sejam incluídos no sistema escolar regular (LDB, 1996).

Embora as leis do sistema educacional brasileiro garantam que os alunos com necessidades especiais sejam incluídos no sistema escolar formal, Mendes (2002/2003) constatou que atualmente existem cerca de 6 milhões de crianças e jovens com necessidades educacionais especiais; porém, considerando a educação especial e a educação geral, o número de matrículas não chega a 400 mil. Rechigo e Marostega (2002) apontam que, quando a educação para surdos-mudos é proposta na educação convencional, surgem várias questões. Muitos se questionam se essa experiência pode ser inserida no contexto sem alterar a representação do público, ou se é mais uma experiência, um terreno mascarado, relacionada à rejeição.

Esse processo é definido por Skliar (2005) como exclusão e inclusão, ou seja, num sistema democrático pluralista, os surdos parecem estar incluídos; no entanto, a exclusão é implementada, na prática, dentro da escola. 
Para evitar a exclusão na escola, o atendimento é ou pode ser complementado por serviços de apoio em salas de recursos, em diferentes turnos, em hospitais, na forma de atendimento domiciliar ou em outros espaços definidos pelo sistema de ensino. Na perspectiva da inclusão, esses aspectos se configuram como ensino fundamental e médio gratuitos.

A legislação educacional promulgada pela Lei $n^{0} 10.098$ de 2000 estipula que o governo deve tomar medidas para eliminar as barreiras da comunicação e garantir que os surdos tenham acesso à informação e à educação, incluindo treinamento para a tradução em linguagem de sinais. Porém, observa-se que, apesar das leis citadas, a maioria das escolas e dos professores ainda não estão preparados para receber alunos surdos.

\section{A QUALIFICAÇÃO DOS PROFESSORES}

A Educação Especial no mundo inteiro é vista como uma emergência para todos, destacando sempre as necessidades que os alunos encontram em sala de aula, tendo apoio de pessoas que reconhecem a importância da Educação Inclusiva para que ela realmente possa acontecer. Com o incentivo recebido dos órgãos educacionais, as conquistas para educandos e educadores servem de estímulo para continuarem a caminhada em busca de educação digna e acessível para todos.

Sabe-se também que a educação não se faz sozinha. Lutar por igualdade de atendimento e de ensino para os alunos é um desafio para os professores, tanto na ausência quanto na presença de alunos surdos em sala de aula. Saber dar-Ihes o atendimento necessário e adequado é processo, é caminho a ser percorrido, que não é, nem será fácil, nem para aluno, nem para o professor. A proposta a ser definida pelo professor deve ser altamente qualificada, para que o estudante possa estar incluído, presente, em todas as atividades dentro e fora da sala de aula.

Dentro dessa temática, pode-se indagar a concepção de inclusão do professor no ensino regular, se continua a mesma ou se muda no decorrer do ano, após receber 
um aluno surdo. Essas concepções podem determinar de fato as atitudes sociais em relação à inclusão do aluno surdo em sala de aula.

Anjos, Andrade e Pereira (2009, p. 122), ao observarem o sentimento dos professores em relação à temática profissional e ao despreparo para lidar com a inclusão ressaltam:

O impacto sentido pelos professores no início do trabalho com alunos deficientes faz com que estes percebam um vazio na sua formação. A falta de um treinamento e o fato de que esses novos sujeitos que estão na sala de aula necessitam de novas capacidades e novos modos de pensar; a certeza de que estão improvisando pode levar os professores a descobrir novos fazeres e novos saberes, não necessariamente subordinados ao 'fazer correto'; as dificuldades encontradas pelo professor podem ajudar a modificar um projeto pedagógico que, por ter-se tornado automático, tornou-se 'fácil'. A necessidade que o professor sente de ser instigado, incentivado diante das dificuldades encontradas e dos desafios colocados induziu-os na busca da sua capacitação.

A vontade do professor de perceber a transformação do aluno a partir das atividades proporcionadas em sala de aula fala mais alto. A percepção de que este aluno precisa mais de sua atenção aponta uma lacuna na sua formação, motivando-o a buscar mais conhecimentos para suprir a carência de informação e de conhecimentos em relação às necessidades do aluno surdo.

Assim, a necessidade de novos conhecimentos e novas experiências a serem vivenciadas instiga a vontade do professor de buscar aperfeiçoamento, para que seja capaz de proporcionar um ensino mais avançado e equilibrado, demonstrando assim coerência entre sua maneira de ser e de ensinar, além da sua acessibilidade e predisposição em relação à integração dos alunos surdos, concebendo-a como um fator extremamente importante e indispensável para a obtenção dos resultados.

Gomes e Barbosa (2006) e de Vitta (2010) apontam a falta de tranquilidade dos professores para lidar com alunos surdos. Segundo eles, uma boa formação é essencial para o bom desenvolvimento dos alunos em sala de aula. Já a falta de formação específica resulta em sensações de incapacidade do profissional que lida 
com crianças surdas. Logo, os professores devem manter-se informados com conteúdos que potencializem sua capacidade profissional.

Ainda, conforme Gomes e Barbosa (2006) e de Vitta (2010), atuar com a diversidade traz para os professores um universo complexo para trabalhar com o novo, pois acontecimentos inesperados podem ocorrer a todo momento. Em se tratando de capacitação dos profissionais que atuam na educação e no acompanhamento de alunos com deficiência auditiva, as atividades devem incluir conteúdos que permitam ao profissional da educação compreender e realizar as atividades propostas.

Como ressalta Dall'Acqua (2007, p. 116), à medida que a inclusão toma espaço nas organizações institucionais educacionais, "torna-se cada vez mais necessário e complexo o processo de formação de professores da educação especial", seja na definição de seus papéis educacionais, seja na consolidação de práticas pedagógicas e de condições profissionais para o enfrentamento de uma realidade em mudança.

Nesta perspectiva, Carvalho (2007) diz que as barreiras enfrentadas no tocante à participação dos alunos na escola é uma característica deles, pois percebe-se que existem dificuldades até nas manobras que devem ser feitas para que se mantenham incluídos na escola, inclusive envolvendo a prática pedagógica.

As modernas teorias sobre aprendizagem e desenvolvimento humano têm nos apontado inúmeras estratégias, que podem tornar a escola um espaço de convivência agradável, de construção de conhecimento e de apropriação dos bens culturais da humanidade, de forma mais prazerosa, não só para os alunos, como para todos os que trabalham nas, ou para a escola, sejam os educadores, os funcionários administrativos, as famílias e a comunidade (CARVALHO, 2007, p. 124).

Para estimular os alunos em sala de aula, é importante a realização de atividades em grupos, que podem ser passadas em aula, a fim de fomentar a vontade de aprender juntos e propiciar o desenvolvimento intelectual dos educandos e capacidade de trabalhar em harmonia. A troca de informações é um fator importante para os alunos com deficiências auditivas.

RC: 96849

Disponível em: https://www.nucleodoconhecimento.com.br/educacao/ensino-delibras 
No que tange ao apoio indispensável aos aprendizes, seus professores e às famílias, a barreira tem sido fazê-los constar dos projetos políticopedagógicos das escolas, não apenas no texto, mas efetivamente funcionando em salas de recursos e/ou com a participação contínua de professores itinerantes, de intérpretes para língua brasileira de sinais ou sob a forma de oferta educacional especializada, fora do espaço escolar, como as classes hospitalares e atendimento domiciliar (CARVALHO, 2007, p. 127).

Os alunos surdos, dispondo de recursos apropriados para sua participação nas aulas, derrubarão enormes barreiras que dificultam sua aprendizagem. Cabe aos educadores contribuir para eliminá-las, garantindo o acesso pleno dos alunos surdos nas escolas, contando com o apoio da família, dos professores e dos que estão à sua volta, principalmente, dos colegas de sala, pois é na escola que devem encontrar o auxílio para as necessidades do dia a dia e que seja permanente o convívio dos alunos surdos nas escolas, sem nenhum tipo de discriminação dos pares.

\section{UMA ESCOLA INCLUSIVA NECESSITA DE ADAPTAÇÕES}

A necessidade de transformar em prática os recursos que veiculam a política de educação para a diversidade, utilizados pelos professores em sala de aula, assentase, de certo modo, na possibilidade de o currículo atender as diferentes necessidades de todos os alunos. Segundo Fernandes (2006, p.17), "é fato que o currículo escolar materializa intenções, crenças e concepções consideradas significativas para a formação dos alunos que se beneficiarão deles".

A instituição, primeiramente, deve preocupar-se com a reputação de seus alunos, oferecendo adaptações que envolvam a realidade de cada um dos que frequentam a escola, com o intuito de contribuir para a superação das desigualdades sociais por eles enfrentadas, isto é, propiciar mais igualdade para todos, respeitando as diferenças e valorizando os educandos que se empenham para serem bemsucedidos na sua uma formação.

Segundo Fernandes (2006, p.18), "esse currículo deve ser o mesmo para todos os alunos, porque, como cidadãos, todos têm o direito à igualdade de oportunidades".

Disponível em: https://www.nucleodoconhecimento.com.br/educacao/ensino-delibras 
Dito isso, a escola inclusiva tem como característica tratar todos da mesma forma, porém incluindo cada um, respeitando sua singularidade, oferecendo-lhe total atenção, dedicação, amor, seguindo o currículo escolar, porém sem promover a exclusão dos alunos com deficiência auditiva.

Segundo Fernandes (2006, p. 18), as habilidades "operacionais em detrimento das intelectuais para uma parcela da população sobreviveu durante séculos nas propostas elitistas que inspiram a história da educação brasileira". O autor cita o exemplo de uma escola que promove a exclusão, ao optar por um currículo em que as atividades pedagógicas em sala de aula exigem menos dos alunos com deficiência, dando a entender que não são capazes e não alcançariam o mesmo nível dos alunos ditos "normais".

A escola para ser caracterizada como inclusiva deve estar preparada com atividades que incluam esses alunos com deficiência. Posto isso, as decisões curriculares devem envolver a equipe da escola para realizar a avaliação, a identificação das necessidades especiais e providenciar o apoio correspondente para o professor e o aluno. Devem reduzir ao mínimo, transferir as responsabilidades de atendimento para profissionais fora do âmbito escolar ou exigir recursos externos à escola (MEC, 1991, p. 41).

Conforme os Parâmetros Curriculares Nacionais (MEC, 1991), as adaptações curriculares não podem ser vistas e entendidas como um processo exclusivamente individual, ou um ato que envolva somente professores e alunos. Para que as adaptações ocorram, é indispensável incrementar o projeto pedagógico, desenvolver o currículo em sala de aula e respeitar a individualidade de cada aluno.

No desenvolvimento curricular dentro de uma escola quando falamos em ação pedagógica, o professor é indispensável, pois é ele que sabe de todas as dificuldades enfrentadas pelos alunos e por ele mesmo em sala de aula, incluindo todos que trabalham para uma escola melhor, não esquecendo os funcionários que merecem ter o seu valor reconhecido também, que sempre estão ali para ajudar no que for preciso para um desenvolvimento correto na escola. Sua importância consiste tanto no que se refere à formação dessas pessoas, através da apropriação do saber, quanto na criação de um espaço real de ação e interação que favoreça o fortalecimento e o enriquecimento da identidade sociocultural (BONETI, 1997, p. 167). 
Portanto, a interação entre esses alunos e destes com outras pessoas à sua volta é uma conquista. À medida que se cria um processo de interação no qual se encontram diferentes grupos familiares, ocorre a comunicação, que beneficia o desenvolvimento social e cognitivo, além de se iniciarem e consolidarem amizades que podem ser para a vida toda. Portanto,

[...] as adaptações curriculares apoiam-se nesses pressupostos para atender às necessidades educacionais especiais dos alunos, objetivando estabelecer uma relação harmônica entre essas necessidades e a programação curricular. Estão focadas, portanto, na interação entre as necessidades do educando e as respostas educacionais a serem propiciadas (MEC, 1991, p. 34).

O trabalho valorizado por um superior é uma forma de engrandecer o seu desempenho que se destaca no meio de muitos. É assim que se deve agir com um aluno surdo para ele sentir-se vitorioso, ou seja, o professor deve priorizar sempre a valorização do desempenho do aluno surdo, pois deve conhecer as dificuldades que ele enfrenta na sala de aula e no convívio na sociedade.

As necessidades especiais revelam que tipo de ajuda, diferente das usuais, são requeridas de modo a cumprir as finalidades da educação. As respostas a essas necessidades devem estar previstas e respaldadas no projeto pedagógico da escola, não por meio de um currículo novo, mas, da adaptação progressiva do regular, buscando garantir que os alunos com necessidades especiais participem de uma programação tão normal quanto possível, mas se considerem as especificidades que as suas necessidades possam requerer (MEC, 1999, p. 34).

Segundo os Parâmetros Curriculares Nacionais (MEC, 1991), sendo o currículo um instrumento que deve servir a todos numa escola de ensino regular, ele pode e deve ser alterado para beneficiar a todos os alunos, inclusive os surdos, a fim de garantirIhes o desenvolvimento pessoal e social.

O currículo é uma ferramenta importante para a escola e para os alunos, para que estes possam desfrutar e aproveitar ao máximo as ações pedagógicas, que constituem a forma concreta para o desenvolvimento de cada um, em sala de aula.

As adaptações curriculares no nível do projeto pedagógico devem focalizar, principalmente, a organização escolar e os serviços de apoio. Elas devem propiciar condições estruturais para que possam ocorrer no nível da sala de

RC: 96849

Disponível em: https://www.nucleodoconhecimento.com.br/educacao/ensino-delibras 
aula e no nível individual, caso seja necessária uma programação específica para o aluno (MEC, 1991, p. 41).

No que diz respeito ao currículo, é preciso atentar sempre nas estruturas físicas da escola, ou seja, não se pode deixar de lado as adaptações necessárias para o desenvolvimento da aprendizagem de todos. Adaptar as escolas é fundamental para que transcorra adequadamente o processo de inclusão, para que alunos e professores alcancem suas metas e aumentem sua autoestima. Portanto, para atender bem os alunos surdos, é indispensável um professor bem qualificado.

$\mathrm{Na}$ reflexão sobre esse assunto, é importante destacar o interesse desses educadores em qualificar-se cada vez mais, para que sejam valorizados pela comunidade escolar. O resultado a ser alcançado por professores capacitados tem como resposta a aceitação dos pais e dos alunos. Assim, a capacitação beneficia tanto o aluno quanto o edu

cador, em termos de experiência e de aprendizagens.

Nesta perspectiva, Mantoan e Prieto (2006, p. 56) destacam que, na LDB de 96, art. 58, III, "são previstos professores com especialização adequada em nível médio ou superior, para atendimento especializado, bem como professores de ensino regular, capacitados para a integração desses educandos nas classes comuns".

Para atender alunos surdos, o professor deve ser especializado, para que tenha condições de trazer para a sala de aula, diversas formas de atividades educacionais e pedagógicas, a fim de tornar a sala mais dinâmica e prazerosa para os alunos que necessitam de apoio e de ajuda para que desenvolvimento escolar seja bemsucedido.

Segundo as Diretrizes Nacionais (BRASIL, 2002a), os professores especializados em educação especial com ênfase na surdez são aqueles que desenvolveram competências para identificarem as necessidades educacionais dos alunos, que conseguem definir e programar respostas educativas para esses alunos, apoiandoos no processo de desenvolvimento da aprendizagem.

RC: 96849

Disponível em: https://www.nucleodoconhecimento.com.br/educacao/ensino-delibras 
As adaptações nas práticas pedagógicas para a inclusão dos alunos surdos demanda a busca por valorização das relações no ambiente escolar. Contudo, sabese que não basta apenas o emprego da LIBRAS pelos docentes e intérpretes para que a inclusão aconteça. Nesse sentido, são esclarecedoras as explicações de (PRÁTICAS, 2011, on-line):

Não há algo pronto para a educação de alunos com deficiência auditiva, mas, com as contribuições da literatura e com a formação e estudos continuados de professores, podemos conhecer práticas pedagógicas que farão toda diferença para a educação de nossos alunos, garantindo assim um direito que é de todos, o de aprender.

Ao tornar-se educador de estudantes surdos, é preciso procurar compreender suas particularidades, uma vez que necessitam de mais atenção no preparo das aulas. Sendo assim, o educador deve buscar, para melhor aproveitamento do conteúdo, estratégias para que seus alunos sejam capazes de compreender o que está sendo comunicado. Por isso, a seleção dos recursos é de essencial importância, uma vez que fazem parte do processo de ensino e aprendizagem, sendo aliados importantes para a prática dos alunos especiais.

$\mathrm{Na}$ sociedade atual, usam-se muito os meios visuais na comunicação, como, por exemplo, a televisão, livros, revistas, outdoors, etc. Logo, são algumas ferramentas que podem ser utilizadas para auxiliar os estudantes surdos, para que entendam os temas trabalhados em aula. Lacerda e Santos (2013, p. 186) asseguram que, "para favorecer a aprendizagem do aluno surdo, não basta apenas apresentar os conteúdos em libras, é preciso explicar os conteúdos de sala de aula utilizando toda a potencialidade visual que essa língua tem". A LIBRAS é uma língua viso-gestual; por isso, deve ser explorada ao máximo para atingir de modo eficaz o aprendizado dos estudantes surdos.

Para Sampaio e Freitas (2011), um dos objetivos do Governo Federal para 2012 era alcançar as necessidades das crianças especiais, proporcionando a todos o acesso à educação, com aporte inclusivo em todas as escolas públicas, estaduais, municipais ou particulares. Contudo, para acontecer uma inclusão real, é preciso 
que todos possam ter a mesma chance profissional e perspectivas de uma carreira acadêmica, para que todos possam exigir seus direitos e cumprir com seus deveres.

Projetos e investimentos que envolvem a inclusão de alunos especiais é a esperança dos que desejam e precisam ser vistos como pessoas normais, no sentido de terem acesso à educação, igualdade de oportunidades, de direito e de justiça. Em outras palavras, é um sonho a ser alcançado por muitos.

De acordo com Sampaio e Freitas (2011, p. 20), "o Plano Nacional dos Direitos das pessoas com Deficiências, o Viver sem Limites, investirá $R \$ 1,8$ bilhões, valor a ser aplicado em ações para promover a acessibilidade nas escolas e garantir a educação".

Lugares que aceitam alunos especiais até existem, mas, normalmente, não contemplam as adaptações corretas e adequadas. Assim sendo, tirar os projetos do papel é fundamental na contemporaneidade, oferecendo materiais e estruturas adequadas, que atendam a demanda destes alunos.

Geralmente, as adaptações contemplam apenas os locais onde os alunos mais transitam na escola, destacando-se as rampas de acesso e os banheiros, que também são os mais procurados pelos pais e pelos alunos, além da acessibilidade nas salas de aula. No entanto, a inclusão não se resume somente à estrutura física na escola e nas salas de aula, mas também envolve um conjunto de ações articuladas, pois, segundo Sampaio e Freitas (2011, p. 20), "é necessário que haja interesse dos pais e que se comprometam a manter os filhos na escola e que os professores se dediquem a educá-los.

Entretanto, é comum nas escolas de ensino regular encontrar salas lotadas, o que é prejudicial para os alunos inclusos. Logo, é fundamental que seja ouvida a opinião de todos a fim de propiciar ajuda a quem precisa tanto da escola. A melhoria das salas de aula em termos de ampliação ou de acomodação dos alunos deve acontecer de forma rápida e precisa, a fim de propiciar cada vez mais um 
desempenho favorável e a motivação dos alunos para frequentarem a escola e se dedicarem aos estudos.

O programa que atende atualmente mais de 24 mil unidades de ensino pelo Brasil foca o desenvolvimento cognitivo, o nível de escolaridade, os recursos específicos para 0 aprendizado e as atividades de complementação e suplementação curricular. No plano anunciado pela então presidente Dilma Roussef, seriam criadas mais de 17 mil salas de recursos multifuncionais (SAMPAIO; FREITAS, 2011, p. 21).

O Governo Federal tem se empenhado em relação à educação inclusiva nas escolas, buscando promover o desenvolvimento cognitivo dos alunos, oferecendo recursos específicos, para construir a continuidade na vida profissional e social.

\section{LIBRAS CONHECIMENTO E RECONHECIMENTO}

A Declaração de Salamanca (1990) reconhece a língua de sinais e a possibilidade de sua utilização para a educação dos surdos, bem como a manutenção dos sistemas especiais de ensino como classes e escolas especiais (BUENO, 2001). Aliada à carta de Salamanca, a estrutura da Libras, segundo Coutinho (2000), é composta por sinais que correspondem a uma palavra, a uma ideia, ou até mesmo a uma frase. Os artigos não são usados na comunicação. A Libras envolve: sinal composto formado por dois ou mais sinais, que representam duas ou mais palavras, mas com uma única ideia, a datilologia (alfabeto manual), que é usado para expressar nomes de pessoas, de localidade ou outras palavras que não possuem um sinal; o sinal soletrado, ou seja, uma palavra da língua portuguesa que, por empréstimo, passou a ser expressa pelo alfabeto manual com uma incorporação de movimento próprio desta língua. Na Libras, os verbos se apresentam no infinitivo.

O método bilíngue traz segurança ao aluno surdo para comunicar-se com outras pessoas e ser inserido na sociedade. Logo, o direito de usar a língua brasileira de sinais contribuiu para que vários estados a usassem.

A LIBRAS não teve reconhecimento somente nos municípios, mas também é amparada pelo Decreto Federal, através da Lei 10.436, de 24 de abril de 2002b, que

RC: 96849

Disponível em: https://www.nucleodoconhecimento.com.br/educacao/ensino-delibras 
dispõe sobre a Língua Brasileira de Sinais (LIBRAS). No Art. $1^{\circ}$, é reconhecida como meio legal de comunicação e de expressão a Língua Brasileira de Sinais - LIBRAS e outros recursos de expressão a ela associados. Parágrafo Único: Entende-se como Língua Brasileira de Sinais - LIBRAS, a forma de comunicação e expressão, em que o sistema linguístico de natureza visual-motora, com estrutura gramatical própria, constitui um sistema linguístico de transmissão de ideias e fatos, oriundos de comunidade surdas do Brasil (Decreto $n^{\circ} 10.436$, de 24 de maio de 2002b).

Isto posto, o reconhecimento de Libras é uma grande conquista, pois passou a ser a língua oficial dos surdos; portanto, os deficientes auditivos são cidadãos como qualquer outra pessoa, tendo os mesmos direitos de estarem integrados na sociedade, especialmente, no contexto da qualificação de professores e em tantos outros contextos profissionais envolvidos, para que haja uma perfeita inclusão em qualquer nível de ensino, a partir da sensibilidade criada no âmbito escolar.

Com a aprovação da LIBRAS, outras medidas foram tomadas para que se tornasse uma disciplina obrigatória em todos os cursos de licenciatura, levando em consideração a reivindicação da comunidade surda para o acesso à educação e ao atendimento bilíngue, priorizando assim a primeira língua dos surdos. O Decreto 5.626, de 22 de dezembro de 2005, diz, no Art. $9^{\circ}$, parágrafo único, que o processo de inclusão de Libras como disciplina curricular deve iniciar-se nos cursos de Educação Especial, Fonoaudiologia, Pedagogia e Letras, ampliando-se para as demais licenciaturas (Decreto $n^{\circ} 5.626$, de 22 de dezembro de 2005).

Para que esse processo seja realidade, é preciso dinamizar e desenvolver projetos em que haja a integração do aluno em âmbito escolar, implementando melhorias na educação oferecida aos alunos surdos. Além disso, é preciso levar aos professores, uma formação continuada de qualidade, adaptando os currículos e implementando novas formas que agreguem ao processo de aprendizado do aluno com surdez, cumprindo assim a lei que rege um sistema educacional de qualidade. 
Nesse sentido, para uma efetiva mudança no ensino, a LIBRAS vem sendo reconhecida como um caminho para os alunos com deficiências auditivas, um reconhecimento que vem de lutas de anos para ganhar espaço não só na escola, mas em toda a sociedade, por ser elemento essencial para a comunicação e para o fortalecimento da identidade surda no Brasil. Logo, a escola não pode ignorar o processo de ensino e aprendizagem dos alunos.

Segundo Quadros e Karnopp (2004), assim como as línguas faladas, as línguas de sinais não são universais; cada país apresenta a sua própria língua. No caso do Brasil, existe a LIBRAS. As autoras manifestam sua preocupação quando se trata de educação dos surdos, pelo fato de LIBRAS ser ainda uma língua deixada de lado por muitos, sendo difícil a sua inserção na escola como segunda língua para os ouvintes e como língua materna para os surdos. LIBRAS não é somente uma linguagem, ela se caracteriza por ser uma língua visual-gestora, isto é, a comunicação não se estabelece pelo canal oral, mas, sim, através da visão e do espaço.

Apesar de haver um bom número de profissionais se especializando para atender alunos surdos, ainda é pouco, pois o que mais se encontra na literatura são referências a professores que desconhecem todas as formas de comunicação com a pessoa surda, porque, no Brasil, ainda é recente a oferta da formação inicial em LIBRAS. Assim, ainda a grande maioria dos educadores não usa essa língua, o que impede, em grande parte, a comunicação entre os pares.

Quando se fala em inclusão, é preciso mencionar a importância de a LIBRAS ser adequada ao currículo escolar, dando total apoio à formação de professores especializados, para que eles favoreçam os ouvintes e os surdos, levando-os à inclusão plena, tornando o ensino apropriado a cada aluno. Nesse sentido, Skliar (2005, p. 27) afirma que "usufruir da língua de sinais é um direito do surdo e não uma concessão de alguns professores e escolas". 
A escola deve-se adequar ao aluno, apresentando alternativas de aprendizagem, independente de suas diferenças, promovendo estratégias para que a Língua Brasileira de Sinais seja sua primeira língua. Ao optar por uma educação inclusiva, a escola é responsável pela adequação do projeto político-pedagógico, para que atenda a todas as necessidades dos alunos, à medida que desenvolve práticas pedagógicas a serem exercitadas no espaço escolar.

\section{CONSIDERAÇÕES FINAIS}

A presente pesquisa de revisão bibliográfica norteou-se em analisar questões inerentes à inclusão do aluno surdo em salas de ensino regular no ensino fundamental. Para alcançar os objetivos desejados, foram analisadas obras científicas relacionadas à temática.

A Declaração de Salamanca (1990) atende as necessidades do aluno surdo; no entanto, nenhuma lei foi e é capaz de fazer acontecer de fato as mudanças necessárias no cerne da sociedade. Assim, ainda há muitos surdos relegados em salas de aula do ensino regular, no ensino fundamental, sem receber o devido acompanhamento, pois a maioria dos educadores não sabe discernir entre o que é inclusão e integração, isto é, procura-se integrar, acreditando que seja incluir.

Para que o aluno surdo seja, no mínimo, melhor acolhido, os educadores deveriam ser capacitados para realizar esse processo, já que não se trata apenas do surdo, mas, sim, de uma sala de aula, geralmente heterogênea, e de um educador para mediar esse conjunto. Se ele não estiver preparado, sendo, no mínimo, conhecedor da LIBRAS, fica praticamente impossível essa inclusão. Assim, o surdo fica relegado a adaptar-se ao contexto, o que é uma tarefa árdua e frustrante para ele. 
Os educadores brasileiros não receberam formação para trabalhar com este público. Além disso, a proposta da inclusão, de certo modo, ainda é recente, bem como os governantes, ao fecharem as escolas especiais e inserirem os alunos surdos no ensino regular, não propuseram uma capacitação com potencial para prepará-los. Com programas de capacitação curtos e pontuais, os professores vêm se desenvolvendo, mas o processo, contudo, ocorre de maneira bastante lenta.

É perceptível que o currículo é um instrumento útil para todos na escola e pode ser alterado para beneficiar os alunos surdos, a fim de garantir-lhes o desenvolvimento pessoal e social. Essas alterações ou adaptações curriculares são de suma importância para a inclusão; porém, há educadores que creem que a não diferenciação no tratamento também seria uma forma de exclusão.

Enfim, fica claro que muito ainda falta para que haja uma verdadeira inclusão do aluno surdo no ensino regular fundamental, devido, principalmente, à falta de políticas públicas direcionadas a esse contexto educacional, sobretudo, falta capacitação de educadores, relativa ao uso e ao funcionamento da LIBRAS, ferramenta essencial para a comunicação com esse aluno e para sua inclusão.

\section{REFERÊNCIAS}

ANJOS, H. P.; ANDRADE, E. M.; PEREIRA, M. R. A inclusão escolar do ponto de vista dos professores: o processo de constituição de um discurso. Rev. Bras. Educ., v. 14 , n. $40,2009$.

BONETI, R. V. F. O papel da escola na inclusão social do deficiente mental. In: MANTOAN, M.T.E. (Org.). A Integração de Pessoas com Deficiência: contribuições para reflexão sobre o tema. São Paulo: Memnon, 1997.

BRASIL. Constituição de 1988. Constituição da República Federativa do Brasil de 1988. Brasília: Presidência da República, [2020]. Disponível em: http://www.planalto.gov.br/ccivil_03/constituicao/constituicao.htm\#: :text=1\%20\%2D 
\%20construir\%20uma\%20sociedade\%20livre,quaisquer\%20outras\%20formas\%20d e\%20discrimina\%C3\%A7\%C3\%A3o. Acesso em: 20 abr. 2021.

BRASIL. Decreto Federal $n^{\circ}$ 5.626, de 22 de dezembro de 2005. Regulamenta a Lei 10.436/2002 que oficializa a Língua Brasileira de Sinais - LIBRAS. Disponível em: http://www.planalto.gov.br/ccivil_03/_ato2004-

2006/2005/decreto/d5626.htm\#: :text=DECRETO\%20N\%C2\%BA\%205.626\%2C\%2 0DE\%2022,19\%20de\%20dezembro\%20de\%202000. Acesso em: 20 mai. 2021.

BRASIL. Diretrizes Nacionais para educação especial na educação básica. 4 . ed. Brasília: MEC, 2002a.

BRASIL. Lei n¹0.436, de 24 de abril de 2002b. Dispõe sobre a Língua Brasileira de Sinais - Libras e dá outras providências. Disponível em: http://www.planalto.gov.br/ccivil_03/leis/2002//10436.htm. Acesso em: 20 mai. 2021.

BRASIL. Lei no 10.098, de 19 de dezembro de 2000. Estabelece normas gerais e critérios básicos para a promoção da acessibilidade das pessoas portadoras de deficiência ou com mobilidade reduzida, e dá outras providências. Disponível em: http://www.planalto.gov.br/ccivil_03/leis/l10098.htm. Acesso em: 10 jan. 2021.

BRASIL. Lei no 9.394, de 20 de dezembro de 1996. Lei de Diretrizes e Bases da Educação (LDB). Brasília: Presidência da República, 1996. Disponível em: http://www.planalto.gov.br/ccivil_03/leis/19394.htm. Acesso em: 10 jun. 2021.

BRASIL. Parâmetros Curriculares Nacionais (PCNs): Estratégias para educação de alunos com necessidades educacionais especiais. Brasília: SEF/SEESP, 1991.

BUENO, J. C. S. Função social da escola e organização do trabalho pedagógico. Educar, Curitiba, n. 17, p. 101-110. 2001.

CARVALHO, Rosita Edler; Educação Inclusiva: Com os Pingos nos “IS”. 5. ed. Porto Alegre: Mediação, 2007. 
COUTINHO, D. Libras e Lingua de Portuguesa (semelhanças e diferenças). São Paulo: Arpoador, 2000.

DALL'ACQUA, M. J. C. Atuação de professores do ensino itinerante face à inclusão de crianças com baixa visão na educação infantil. Paidéia, v. 17, n. 36, 2007.

DE VITTA, F. C. F. A inclusão da criança com necessidades especiais na visão de berçaristas. Cadernos de Pesquisa, v. 40, n. 139, p. 75-93, 2010.

DECLARAÇÃO DE SALAMANCA E LINHA DE AÇÃO SOBRE NECESSIDADES EDUCATIVAS. Brasília: Ministério da Educação,1990.

FERNANDES, Sueli. Metodologia da Educação Especial. São Paulo: Fotoleser Gráfica e Editora, 2006.

GOMES, C.; BARBOSA, A. J. G. A inclusão escolar do portador de paralisia cerebral: atitudes de professores do ensino fundamental. Rev. Bras. Ed. Esp., v.12, n.1, p. 85-100, 2006.

LACERDA, C. B. F; SANTOS, L.F. Tenho um aluno surdo. E agora?: Introdução à Libras e educação de surdos. São Carlos: EdUFScar, 2013.

MANTOAN, Maria Teresa Égler; PRIETO, Rosangela Gavioli. Inclusão Escolar: pontos e contrapontos. São Paulo: Summus, 2006.

MATO GROSSO. Educação Básica do Mato Grosso. Cuiabá: Estado do Mato Grosso, 2002.

MENDES, E.G. A educação inclusiva e a universidade Brasileira. Revista Espaço. Rio de Janeiro, v. 18/ 19, p. 42-44, 2002/2003.

ORGANIZAÇÃO DAS NAÇÕES UNIDAS (ONU). Declaração dos Direitos Humanos. Genebra: Unicef, $1948 . \quad$ Disponível em: 
https://www.unicef.org/brazil/declaracao-universal-dos-direitos-humanos. Acesso em: 20 m1r. 2021.

PEIXOTO, Maria Angélica. Inclusão ou Exclusão: o dilema da educação especial. Goiânia: Germinal, 2002.

PRÁTICAS PEDAGÓGICAS para educação de alunos com deficiência auditiva. 06 dez. 2011. Disponível em: https://edspec.wordpress.com/2011/12/06/praticaspedagogicas-para-educacao-de-alunos-com-deficiencia-auditiva/ Acesso em: 30 jul. 2021.

QUADROS, Ronice Muller de; KARNOPP, Lodenir Becker. Língua de Sinais Brasileira: estudos linguísticos. Porto Alegre: Artmed, 2004.

RECHIGO, C. F.; MAROSTEGA, V. L. (Re) pensando o papel do educador especial no contexto da inclusão de alunos surdos. Revista Educação Especial, n. 19, p. 14, 2002.

SAMPAIO, S.; FREITAS, I. B de (Orgs.). Transtornos e dificuldades de aprendizagem: entendendo melhor os alunos com necessidades educativas especiais. Rio de Janeiro: Wak, 2011.

SKLIAR, Carlos; A Surdez, um olhar sobre as diferenças. 3. ed. Porto Alegre: Mediação, 2005.

STROBEL, K. L. Projeto de mestrado surdos: vestígios culturais não registrados na história. Florianópolis: UFSC, 2006.

Enviado: Junho, 2021.

Aprovado: Setembro, 2021. 